\title{
Development of Data Acquisition System Using LabVIEW-based Interface for Aircraft Application
}

\author{
Faaris Mujaahid ${ }^{* 1}$, Fuad Hammaminata Arya Anjasmara ${ }^{1}$, Rama Okta Wiyagi ${ }^{1}$, Karisma Trinanda \\ Putra $^{2}$ \\ ${ }^{1}$ Department of Electrical Engineering, Faculty of Engineering, Universitas Muhammadiyah Yogyakarta, Indonesia \\ Bantul 55183 Daerah Istimewa Yogyakarta, Indonesia \\ ${ }^{2}$ College of Information and Electrical Engineering, Asia University \\ Liufeng Road 500, Wufeng District, Taichung City, Taiwan 41354 \\ *Corresponding author, e-mail: f.mujaahid@umy.ac.id
}

\begin{abstract}
This paper discusses an interface data acquisition (DAQ) of a rocket using LabVIEW. The software development is meant to improve the quality and reliability of the interface that has been built by the UMY rocket team. The data used on the experiments is a set of dummy data created for simulation purpose. This data is generated by Arduino UNO, in which it was acquired by LabVIEW through VISA serial communication platform. The test results show that there is $10 \%$ error during the data retrieval. The $D A Q$ average speed is 270 milliseconds. This new approach has more stable and reliable system when compared to previous algorithm.
\end{abstract}

Keywords: DAQ, LabVIEW, Arduino, Rocket

\section{Introduction}

Along with the development of technology, aeronautics and astronautics become one of the parameters to measure the level of technology and science of a country, including Indonesia. The Indonesian government believes that the research development on these fields will have a significant impact on the scientific and economic sectors. Therefore, the government, through LAPAN (National Aeronautics and Space Institute) and Kemenristekdikti (Ministry of Research, Technology, and Higher Education of Indonesia) holds an annual competition called KOMURINDO (Indonesian Rocket Contest Competition) with the aim to spur rocket research in higher education, such as universities and polytechnics. Since 2008, this competition has been held ten times and every year the participants are increasingly competitive [1][8]. Universitas Muhammadiyah Yogyakarta rocket team participated in Komurindo 2018 with improvements in the communication sector. This is due to the technology used in the previous competitions had a stability problem in the interface system to display the rocket sensor readings [2].

In a research article published in 2012, LabVIEW is used in control system engineering education [3]. The data acquisition is used to provide better performance of model predictive control (MPC). The three methodologies to differentiate MPC for a simple model, simple model with time delay, and MPC versus PID controller are using LabVIEW to simulate the results and explain the performance of the MPC [3].

This paper contains an important development for the system communication interface and involves the signal acquisition from the sensors part to the ground control system (LabVIEW-PC). Therefore, the scope of this paper is data acquisition conducted using the LabVIEW interface with dummy data as a substitute for the original data. Unlike a text-based programming language interface or command-line interface (CLI), this research uses LabVIEW which is based on graphical-based programming. The reminder of this paper is organized as follows; the method is described in section 2, experiments and results are presented in section 3 , and section 4 concludes the paper. 


\section{Design of Interface using LabVIEW}

The software tool used in this work is LabVIEW 2017 32-bit (Version 17.0). This program is a graphical-based programming software produced by National Instruments. LabVIEW program is known as VI or Virtual Instruments because its appearance and operation can mimic an instrument. In LabVIEW, there are two parts, i.e. Front Panel and Block Diagram. The interface is the Front Panel, while the source code is worked out in the backend layer, namely Block Diagram. Figure 3 shows the design of the Front Panel from LabVIEW. From this window design, there are six smaller sections available to separate difference functions. Explanations of each section are in Table 2.

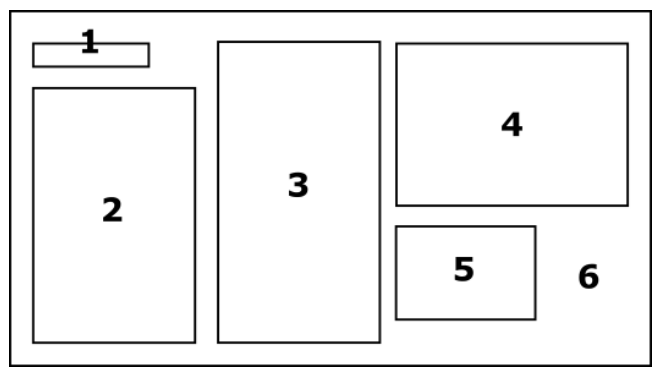

Fig. 3. Design of LabVIEW interface

TABLE II

DESCRIPTION FOR EVERY FIELDS SHOWN IN FIGURE 3

\begin{tabular}{cl}
\hline \hline No. & \multicolumn{1}{c}{ Function } \\
\hline $\mathbf{1}$ & Determine the serial communication port \\
$\mathbf{2}$ & Output indicator after processing \\
$\mathbf{3}$ & $\begin{array}{l}\text { Initial data indicators that are still in one } \\
\text { package }\end{array}$ \\
$\mathbf{4}$ & $\begin{array}{l}\text { Indicator data after fragmentation and } \\
\text { processing time }\end{array}$ \\
$\mathbf{5}$ & Output error indicator \\
$\mathbf{6}$ & Front panel window \\
\hline \hline
\end{tabular}

LabVIEW is used as a tool for data acquisition. This process requires a feature called VISA (Virtual Instrument Software Architecture). VISA or often also called NI-VISA can use many types of data communications such as GPIB, USB, Serial, and Ethernet [4]. In this project, VISA is used for Serial communication.

Figure 4 shows a flowchart that was designed using LabVIEW to run the data acquisition mechanism. This process also involves Global Variables, where it acts as a means of virtual access and filter data through several VIs running simultaneously. This feature is built-in within LabVIEW and only has block diagrams to design with.

The algorithm flow of DAQ in LabVIEW is as shown in figure 4 which includes the data reading, scanning and filtering of unwanted data (ovf, nan), data parsing, filtering out the error messages, and data display on Front Panel.

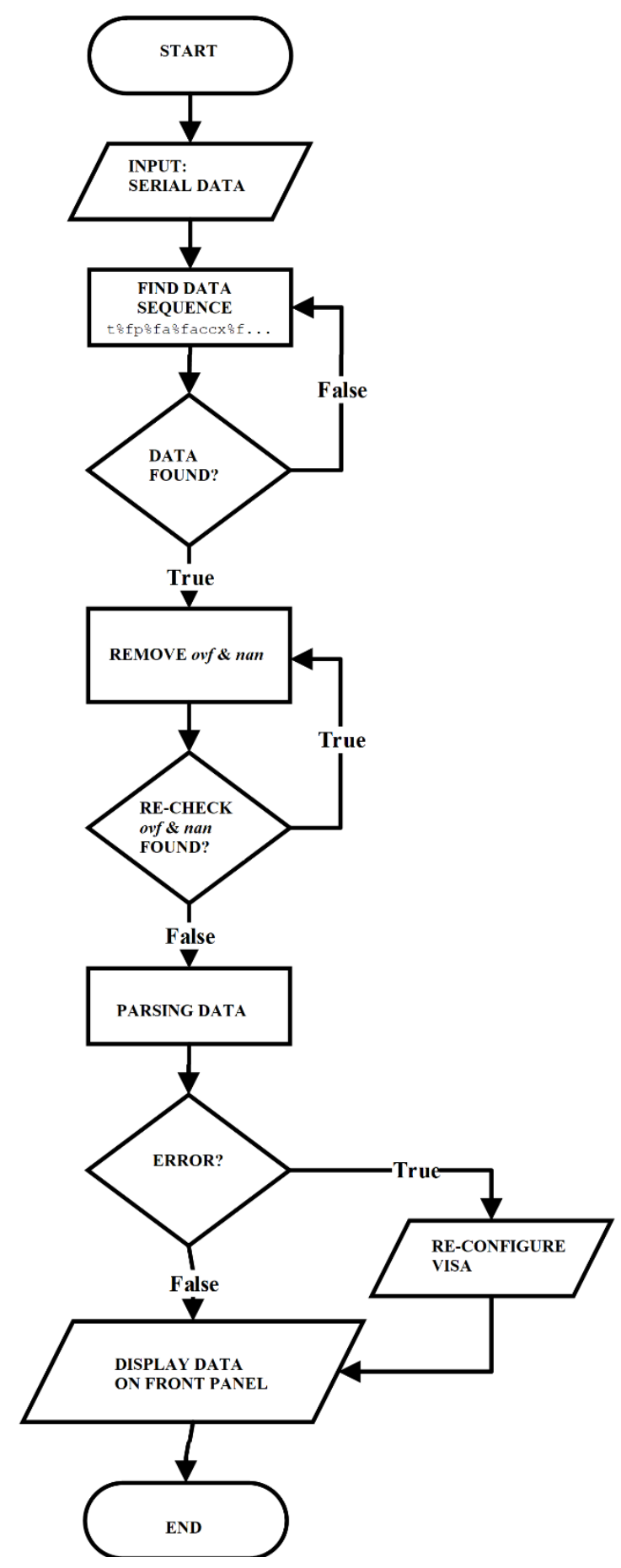

Fig. 4. Flowchart of DAQ algorithm

\section{Experiments and Results}

The simulation is carried out using two approaches. The first approach is to check the 
quality of data communication, while the second is to see the reliability of data communication.

\section{A. System Quality}

Before entering LabVIEW interface testing, it is necessary to check the data through Serial Monitor. This check is carried out to ensure that the data communication from Arduino UNO is still in good quality. The following are the results of the dummy data displayed on the Serial Monitor. From the results of serial data monitoring, it shows that the data communication on Arduino UNO is going well, proven by the presence of dummy data on the display. Dummy data is displayed continuously, with no separator in the form of Enter.

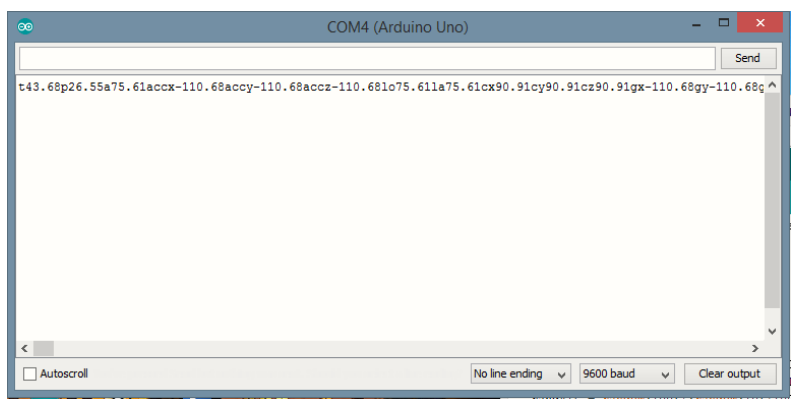

Fig. 5. Result of dummy data in Arduino Serial Monitor

After the dummy data is obtained, communication between Arduino UNO and LabVIEW can be done. This is done using the VISA feature, as stated earlier. The following shows the Front Panel interface after running.

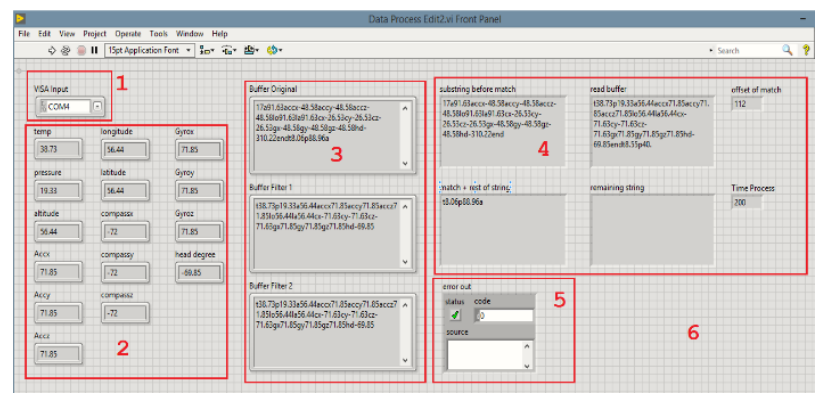

Fig. 6. Display of Front Panel

Figure 6 shows the data processing through indicators in the form of parameters that are processed, starting from raw data to real data. Raw data is in the form of dummy data that has been partially retrieved from serial communication using the VISA feature. As stated in the interface design, the function of LabVIEW above works according to what was planned earlier in the Methodology section. Chronologically, the process order based on Figure 3 and 6, we get the sequence of 3-4-5-2.

\section{B. System Reliability}

After checking the work quality of the system, the outputs of the system need to be considered. LabVIEW is run 50 times to see the system's efficiency in data acquisition. The following Table 3 shows the results of data retrieval.

TABLE III

EXPERIMENT OF DATA PARSING MECHANISM

\begin{tabular}{|c|c|c|c|}
\hline $\begin{array}{c}\text { Experiment } \\
\text { No. }\end{array}$ & $\begin{array}{c}\text { Processing } \\
\text { Time } \\
\text { (milisecond) } \\
\end{array}$ & Error & $\begin{array}{c}\text { Position of } \\
\text { Error } \\
\text { (data seq. n-th) }\end{array}$ \\
\hline 1 & 400 & No & - \\
\hline 2 & 300 & No & - \\
\hline 3 & 100 & Yes & 10 \\
\hline 4 & 200 & No & - \\
\hline 5 & 300 & No & - \\
\hline 6 & 300 & No & - \\
\hline 7 & 200 & No & - \\
\hline 8 & 200 & No & - \\
\hline 9 & 800 & No & - \\
\hline 10 & 300 & No & - \\
\hline 11 & 200 & No & - \\
\hline 12 & 200 & No & - \\
\hline 13 & 500 & No & - \\
\hline 14 & 200 & No & - \\
\hline 15 & 100 & No & - \\
\hline 16 & 100 & Yes & 4 \\
\hline 17 & 700 & No & - \\
\hline 18 & 200 & No & - \\
\hline 19 & 200 & No & - \\
\hline 20 & 200 & No & - \\
\hline 21 & 200 & No & - \\
\hline 22 & 800 & No & - \\
\hline 23 & 200 & No & - \\
\hline 24 & 600 & No & - \\
\hline 25 & 200 & No & - \\
\hline 26 & 300 & No & - \\
\hline 27 & 200 & No & - \\
\hline 28 & 200 & No & - \\
\hline 29 & 100 & Yes & 12 \\
\hline 30 & 200 & No & - \\
\hline 31 & 100 & No & - \\
\hline 32 & 200 & No & - \\
\hline 33 & 500 & No & - \\
\hline 34 & 600 & No & - \\
\hline 35 & 200 & No & - \\
\hline 36 & 100 & Yes & 3 \\
\hline 37 & 300 & No & - \\
\hline 38 & 200 & No & - \\
\hline 39 & 500 & No & - \\
\hline 40 & 200 & No & - \\
\hline 41 & 100 & Yes & 10 \\
\hline 42 & 200 & No & - \\
\hline 43 & 200 & No & - \\
\hline 44 & 200 & No & - \\
\hline 45 & 100 & No & - \\
\hline 46 & 200 & No & - \\
\hline 47 & 500 & No & - \\
\hline 48 & 200 & No & - \\
\hline 49 & 200 & No & - \\
\hline 50 & 200 & No & - \\
\hline
\end{tabular}


The grey-marked data is the data with error occurred in the n-th data format (refer to table 1). For example, position of error 10 means that the error occurs on data format $c y$ or compass data $y-$ axis. In 50 data retrievals, five errors were found. Hence, using the following equation, error possibility can be retrieved.

$$
\text { error }=\frac{n \text { error }}{n \text { datum }}=\frac{5}{50}=\frac{1}{10}=10 \%
$$

From this system, an error of $10 \%$ is obtained and this is still acceptable or tolerated. This error is caused by data that failed to split due to incomplete format according to the format above. This is indicated in the Error Position column, where there is a possibility of data loss between the first variable up to the fifteen, due to the delay of reading or due to serial communication that is sometimes interrupted. Then, the system takes less than 1 second (1000 milliseconds), which is between 100 900 milliseconds. The following is an average calculation.

$$
t_{\text {average }}=\frac{\text { proccess time }}{n \text { datum }}=\frac{13500 \mathrm{~ms}}{50}=270 \mathrm{~ms}
$$

The system works with an average speed of 270 milliseconds and this is fast enough for the reading of a payload rocket instrument in competition.

\section{Conclusion}

From the experimental results, it may be concluded that the design of DAQ interface by using dummy data in LabVIEW accordingly works well. Data generated from the Arduino UNO could act as the original data. The process includes the VISA serial communication, data reading, scanning, filtering, and VISA reconfiguration. For future works, error handling needs to be optimized to get less error and more accurate results.

\section{References}

[1] Mujaahid, F., Hizbullah, A. M., Syahfitra, F. D., Dahlan, M. A., Juliansyah, N. D. (2017). Development of User Interface Based on LabVIEW for Unmanned Aircraft Application. Journal of Electrical Technology UMY (JET-UMY), Vol. 1, No. 2, 106.

[2] Balaji, V. (2012). Study of Model Predictive Control Using NI LabVIEW. International Journal of Advanced Research in Engineering and Technology, Vol. 3, Issue 2, pp. 257-266.

[3] National Instruments (2018). NI-VISA Overview. Retrieved January 6, 2018
[4] National Instruments (2018). Global Variable. Retrieved February 1, 2018

[5] Wiyagi, R. O., Danardono, Agus, T. A. (2017). High Altitude Balloon Payload Design for Atmospheric Observations. Journal of Electrical Technology UMY (JET-UMY), 1(1). 50-57.

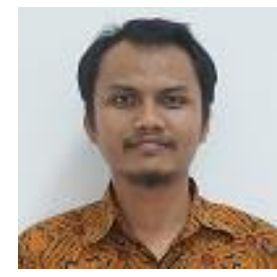

\section{Authors' information}

Faaris Mujaahid Hold a bachelor degree in 2010 from Electrical and Electronics Engineering Department, Saxion University of Applied Sciences, the Netherlands. He received a master degree in Sustainable Energy Technologies in 2016 from University of Southampton, UK. ing. Faaris Mujaahid, M.Sc is currently a lecturer in the Department of Electrical Engineering, Faculty of Engineering, Universitas Muhammadiyah Yogyakarta, Indonesia. His main research interest is in LabVIEW and renewable energy (mainly in solar cell material and fabrication technologies).

Fuad Hammaminata Arya Anjasmara is a bachelor student of Electrical Engineering, Faculty of Engineering, Universitas Muhammadiyah Yogyakarta, expected to finish his study in 2019.

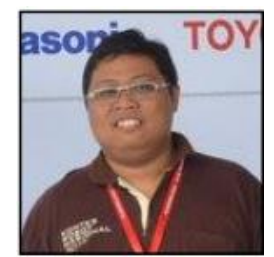

Rama Okta Wiyagi Received B.Sc degree from Department of Electrical Engineering Universitas Muhammadiyah Yogyakarta in 2009, M.Eng. degree from Department of Electrical Engineering and Informatics Technology, Universitas Gadjah Mada, Yogyakarta, Indonesia in 2014. Rama Okta Wiyagi, M.Eng. is a Lecturer in Department of Electrical Engineering, Faculty of Engineering, Universitas Muhammadiyah Yogyakarta, Indonesia. His research interests are in robotics, robotics vision and instrumentation.

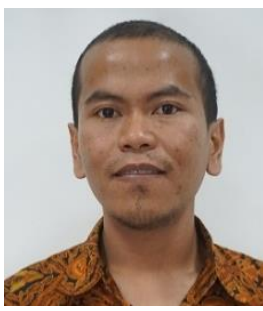

Karisma T. Putra born in Bondowoso on June 19, 1990. Graduated from elementary to senior high school in Bondowoso until 2008. Studied bachelor degree program in Surabaya, precisely in Electronics Engineering Polytechnic Institute of Surabaya (EEPIS) until 2012. He got scholarship program to continue master degree in Institut Teknologi Sepuluh Nopember (ITS) Surabaya. Karisma is also a lecturer at Electrical Engineering, Faculty of Engineering, Universitas Muhammadiyah Yogyakarta. The main focus of research is the intelligent systems and controls. He engaged in joint research related to the development of food commodity tracking systems and integrated intelligent systems. He was involved in several competitions in developing smart devices. Pursue the field of electronics and software development since college. Mr. Putra joined in Indonesian's engineer union organization (PII) in 2016. Mr. Putra is also active in writing publications on IEEE society. 